\title{
Study of plasmonic effect in silicon solar cells with silver nanoparticles
}

1 Komiljon Yakubov PhD*

Deputy Director, Urganch branch of Tashkent Medical Academy, Urganch, Uzbekistan

2 Jaksilik Zhanabergenov PhD

Senior Teacher, Department of Physics, Nukus State Pedagogical Institute named after A'jiniyaz, Nukus, Karakalpakstan, Uzbekistan
$3 \quad$ Sharibay Turemuratov PhD

Principal Scientist, Complex Institute of Natural Sciences, Karakalpak Branch of Uzbekistan Academy of Sciences, Nukus, Karakalpakstan, Uzbekistan

4 Usnatdin Ernazarov MPhil

Senior Researcher, Complex Institute of Natural Sciences, Karakalpak Branch of Uzbekistan Academy of Sciences, Nukus, Karakalpakstan, Uzbekistan
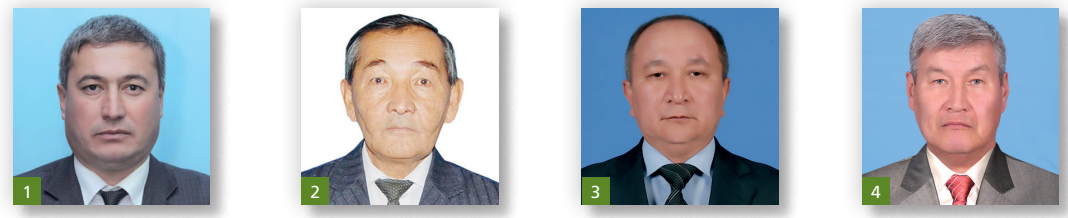

This article presents a study of the plasmonic effect of small-size silver nanoparticles in silicon (Si)-based solar cells. The particles were deposited on the surface of Si by the thermal evaporation method. The size of the particles and their distribution was studied using scanning electron microscopy. It is shown that the largest particle size was $\approx 32 \mathrm{~nm}$. The samples were capped by $\mathrm{SiO}_{\mathrm{x}}$ or $\operatorname{SiN}_{\mathrm{x}^{\prime}}$ and reflectance spectra measured. It was found that the reflectance decreases with increasing silver nanoparticle diameter. Annealing at $375^{\circ} \mathrm{C}$ did not cause qualitative change of the reflectance spectra. The particles were deposited on Si solar cells, and current-voltage dependence was measured.

\section{Introduction}

Most modern silicon $(\mathrm{Si})$ solar cells are wafer-based, with thickness in the range $180-300 \mu \mathrm{m}$. The cost of the cells makes up $\approx 40 \%$ of the final module price. For further reduction of the cost, it is necessary to reduce the thickness of $\mathrm{Si}$ to as little as $\approx 2 \mu \mathrm{m}$. However, $\mathrm{Si}$ is well known as an indirect band gap semiconductor, and its absorption coefficient of photons with energies near to the band edge is $<10^{-4} / \mathrm{cm}$. As a result, a thin $\mathrm{Si}$ film of thickness $\approx 2 \mu \mathrm{m}$ absorbs a smaller amount of energy from sunlight than the 180-300- $\mu$ m wafer. ${ }^{1}$ Consequently, the efficiency of the thin-film Si cells would be less than that of waferbased Si cells. To enhance the light-absorbing properties of the active part of the cells, it is necessary to incorporate other material(s) with improved light-absorbing properties, or some other methods should be applied. One such method is increasing the optical path of the sunlight inside $\mathrm{Si}$. In $\mathrm{Si}$ wafers, it can be achieved by texturing the surface, which has led to good results. ${ }^{2}$ However, this method cannot be applied to $\mathrm{Si}$ cells, because the height of the pyramids in the texturized surface is $\approx 3-8 \mu \mathrm{m}$, which exceeds the thickness of the wafer. A method has been suggested in refs. $3-5$, which is based on light trapping by plasmonic effect. Plasmons are the type of waves that are excited on nanostructures of some metals by incident sunlight and move through the electrons at the surface of a metal. The plasmons formed at the surface of the particles deflect the photons under different angles so that they bounce back and forth within the cell, thus increasing the optical path length of the light and allowing longer wavelengths to be absorbed. ${ }^{6,7}$ Silver and gold are the most suitable metals for these purposes. ${ }^{8,9}$ Extensive research has previously been performed and interesting results have been reported. Reference 10 reports an enhancement of photovoltage in a graphene semiconductor structure due to the plasmonic effect. The efficiency of photodetectors has been increased by $\approx 20$ times. By analysis of different mechanisms, it has been shown that the enhancement due to plasmonic effect was not because of the increase of the path length of photons, but because of the efficient field concentration in the area of a $p-n$ junction. ${ }^{11}$ The size and shape of the nanoparticles are found to play important roles in plasmonic effect to tune it from near ultraviolet (UV) and far out in the infrared (IR) spectrum. ${ }^{6}$ The nanoparticles can be fabricated by many ways such as, for example, lithographic techniques, thermal deposition, 


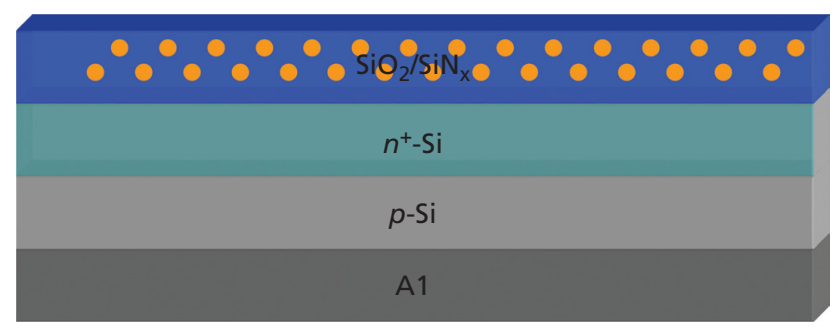

Figure 1. Schematic representation of Si solar cells with silver nanoparticles capped with $\mathrm{SiO}_{2}$ or $\mathrm{SiN}_{x}$

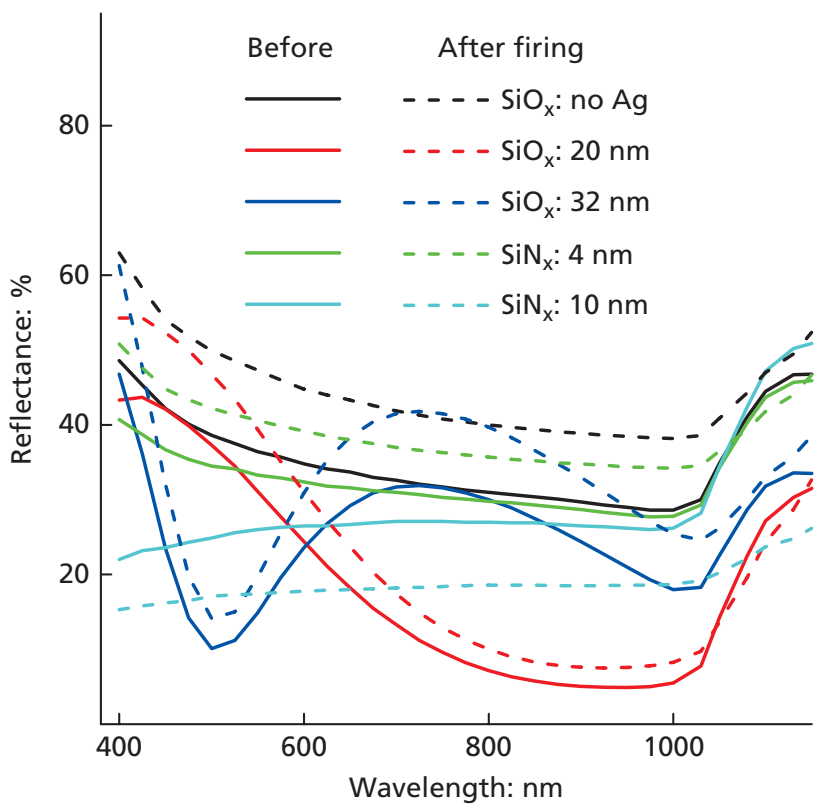

Figure 2. Reflectance spectra of Si with and without silver nanoparticles capped by $\mathrm{SiO}_{x}$ and $\mathrm{SiN}_{x}$ layers before and after firing

vapor phase reactions, aerosol thermolyses, plasma atomization, vapor deposition and wet chemical route. The chemical precipitation from solution, plus thermal deposition, is probably the easiest and cheapest method. ${ }^{12}$ The aim of this work is to use thermal evaporated silver nanoparticles to investigate the influence of plasmonic effect on $\mathrm{Si}$ solar cells. Particular attention is given to the deposition of silver nanoparticles on different substrates and to different Si solar cell structures and their stability with respect to thermal processing.

\section{Methods}

Silver nanoparticles were deposited by thermal evaporation method. Particle size and shape were investigated using a Hitachi S-4800 scanning electron microscope. Process parameters such as deposited silver thickness and time and temperature of the annealing step were investigated. Optical properties of the samples were characterized using an Ocean Optics HL-2000-FSHA optical microscope with a

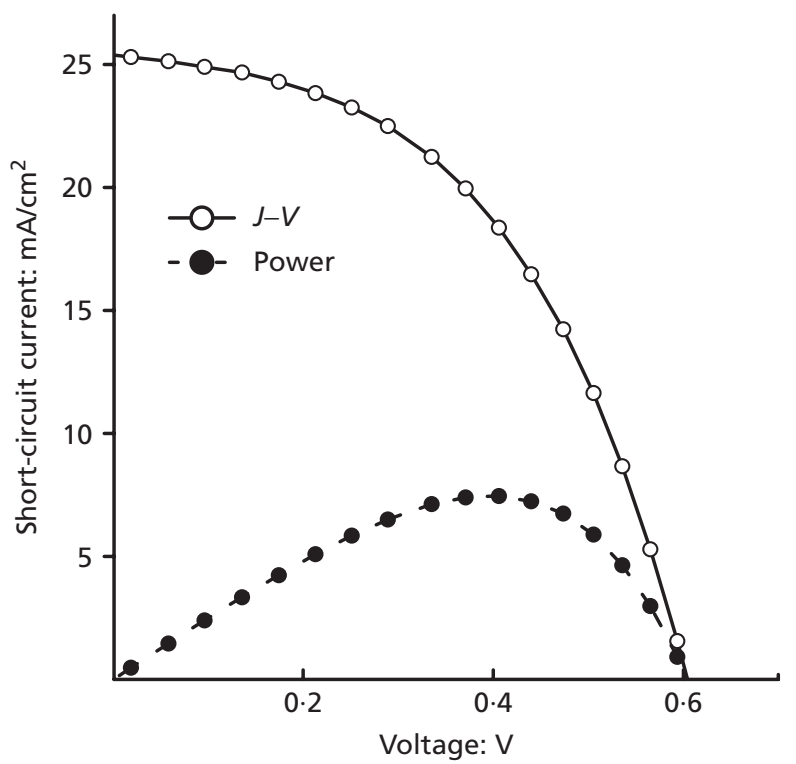

Figure 3. Current-voltage dependence of the Si solar cells with silver nanoparticles deposited from front side underneath the $\operatorname{SiN}_{x}$ layer

\begin{tabular}{|c|c|c|c|c|}
\hline $\begin{array}{l}\text { Annealing } \\
\text { time : min }\end{array}$ & $V: \mathbf{V}$ & $J_{s c}: m A / c^{2}$ & $\begin{array}{c}\text { Fill } \\
\text { factor }\end{array}$ & $\begin{array}{c}\text { Efficiency: } \\
\%\end{array}$ \\
\hline \multicolumn{5}{|c|}{ Silver nanoparticles covered by $\operatorname{SiN}_{x}$} \\
\hline $0 \cdot 37$ & $0 \cdot 60$ & $23 \cdot 54$ & 0.58 & $8 \cdot 21$ \\
\hline $1 \cdot 13$ & $0 \cdot 60$ & $25 \cdot 39$ & 0.49 & $7 \cdot 46$ \\
\hline $2 \cdot 02$ & 0.61 & $28 \cdot 82$ & $0 \cdot 50$ & $8 \cdot 84$ \\
\hline $3 \cdot 15$ & $0 \cdot 62$ & $32 \cdot 38$ & $0 \cdot 52$ & $10 \cdot 27$ \\
\hline \multicolumn{5}{|c|}{ Silver nanoparticles covered by $\mathrm{SiO}_{x}$} \\
\hline $2 \cdot 00$ & 0.60 & $19 \cdot 87$ & 0.50 & $6 \cdot 12$ \\
\hline $3 \cdot 15$ & 0.62 & $19 \cdot 41$ & $0 \cdot 28$ & $3 \cdot 32$ \\
\hline $5 \cdot 00$ & 0.62 & 0.45 & $0 \cdot 25$ & 0.07 \\
\hline
\end{tabular}

Table 1. Performance of Si solar cells with silver nanoparticles covered by $\mathrm{SiN}_{x}$ or $\mathrm{SiO}_{2}$ layers after thermal processing for different annealing time

light source of wavelength in the range $260-2000 \mathrm{~nm}$. The surface of the wafers was polished. The thickness of the wafers considered in this article is about $300 \mu \mathrm{m}$. The wafers were cut by laser into smaller $1-2 \mathrm{~cm}^{2}$ structures. Before thermal evaporation, the samples were washed in distilled water and dried in an atmosphere of $\mathrm{N}_{2}$. Si solar cells were prepared with silver nanoparticles capped with $\mathrm{SiO}_{2}$ or $\mathrm{SiN}_{\mathrm{x}}$ (Figure 1). Current-voltage characteristics $(J-V)$ of the $\mathrm{Si}$ solar cells were investigated. Annealing was performed on a hot plate with a ceramic surface in an $\mathrm{N}_{2}$ atmosphere at $375^{\circ} \mathrm{C}$ within $0 \cdot 3-4 \cdot 0-\mathrm{min}$ intervals. 


\section{Results}

Silver nanoparticles of different sizes were deposited on $\mathrm{Si}$ substrates. The size and shape of the particles are not regular. Surrounding the particles with circles, the average diameter of the particles was estimated to be $\approx 30 \mathrm{~nm}$. The analysis showed that the diameter of the particles increases linearly with increasing thickness of silver. The maximum size of the particles obtained in this work is $\approx 32 \mathrm{~nm}$. Shape of the nanoparticles is also non-uniform and is close to an ellipse.

After the analysis of their size and shape, the nanoparticles were capped. Two different capping layers, $\mathrm{SiO}_{x}$ and $\mathrm{SiN}_{x}$, were used. Reflectance spectra of the capped and non-capped samples were studied before and after thermal processing. The results are presented in Figure 2. Analysis shows that the reflection spectra strongly depend on particle size and on capping material. Without firing, the reflectance from both $\mathrm{SiO}_{\mathrm{x}}$ - and $\mathrm{SiN}_{\mathrm{x}}$-capped samples decreases with increasing silver nanoparticle diameter. In the $\mathrm{SiO}_{x}$-capped samples with a particle size of $\approx 20 \mathrm{~nm}$, a peak located at $\approx 750 \mathrm{~nm}$ is seen. Annealing at $375^{\circ} \mathrm{C}$ did not lead to qualitative change in the reflectance spectra, and it remained smaller than for the samples not containing the silver nanoparticles. On the one hand, this could be due to the influence of the capping layer; on the other hand, it could be because of the smaller size of the silver nanoparticles. The silver nanoparticles of diameter between 4 and $10 \mathrm{~nm}$ were capped with $\mathrm{SiN}_{\mathrm{x}}$. Reflectance spectra for the samples are smaller than for those without silver and decrease with increasing particle diameter. On annealing at $375^{\circ} \mathrm{C}$, reflectance spectra of the 10-nm-diameter samples decreased further. This is in contrast to the samples capped by $\mathrm{SiO}_{x}$, which exhibited annealinginduced increase of reflectance. This result is probably related to oxidation of silver nanoparticles in the $\mathrm{SiO}_{\mathrm{x}}$-capped samples.

In addition to the above-documented findings, the largest silver nanoparticles were deposited on top of Si solar cell structures with aluminum back contact. Figure 3 shows the $J-V$ curve of one of the samples with silver nanoparticles. The efficiency of the cells is $\approx 10.30 \%$. The open-circuit voltage $\left(V_{\text {oc }}\right)$ is $0.61 \mathrm{~V}$, the shortcircuit current $\left(J_{\mathrm{sc}}\right)$ is $32.4 \mathrm{~mA} / \mathrm{cm}^{2}$, the fill factor $(\mathrm{FF})$ is $52 \%$ and the optimal power $\left(P_{\text {opt }}\right)$ is $1026 \mathrm{~mW} / \mathrm{cm}^{2}$. Analysis showed that the efficiency of the cells with silver nanoparticles was less than the efficiency of cells without the particles. Probably, it is related to the smaller size of the silver nanoparticles, because light absorption is enhanced. Really, the color of the cells has been changed from bluish to greenish.

The influence of thermal annealing on electrical parameters was studied at different annealing temperatures for cells with silver nanoparticles capped by $\mathrm{SiN}_{x}$ and $\mathrm{SiO}_{2}$. The results are shown in Table 1 for $V_{\mathrm{oc}}, J_{\mathrm{sc}}, \mathrm{FF}$ and $P_{\mathrm{opt}}$. Analysis showed that the performance of the cells with silver nanoparticles increases with increasing annealing time if the cells are capped by $\mathrm{SiN}_{x}$ and decreases if capped by $\mathrm{SiO}_{2}$. The silver nanoparticles were also deposited on the back side of Si. Subsequently, the cells were capped by $\mathrm{Al}$ contact by magnetron sputtering. The efficiency of the cell was much lower than those without the silver nanoparticles. The authors suggest that this is due to smaller size of the particles. The increase of the photocurrent due to the plasmonic effect has been reported previously in many studies. However, in these articles, the average diameter of the nanoparticles is much larger than those in the present work.

\section{Conclusion}

In this work, the authors studied silver nanoparticles deposited by thermal evaporation for Si solar cell applications. Study of the morphology by scanning electron microscopy shows that the shape and size of the particles are not uniform, and the average diameter has been estimated. The maximum average diameter achieved was found to be $\approx 32 \mathrm{~nm}$. It is established that the diameter of the nanoparticles increases with increasing thickness of silver. Reflectivity spectra of $\mathrm{Si}$ with silver nanoparticles capped and not capped by $\mathrm{SiN}_{\mathrm{x}}$ and $\mathrm{SiO}_{2}$ has been studied. It has been shown that the reflectivity spectra decrease with increasing diameter of silver nanoparticles. Annealing at $375^{\circ} \mathrm{C}$ did not lead to qualitative changes in the reflectivity spectra. Particles were deposited on the surface of silicon solar cells, and currentvoltage dependence was studied.

\section{REFERENCES}

1. Atwater, H. A.; Polman, A. Plasmonics for improved photovoltaic devices. Nature Materials 2010, 9, 205-213.

2. Green, M. Thin-film solar cells: review of materials, technologies and commercial status. Journal of Materials Science 2007, 18, 15-19.

3. Catchpole, K. R.; Pillai, S. Absorption enhancement due to scattering by dipoles into silicon waveguides. Journal of Applied Physics 2006, 100, 044504.

4. Catchpole, K. R.; Pillai S. Surface plasmons for enhanced silicon light-emitting diodes and solar cells. Journal of Luminescence 2006, 121, 315-318.

5. Catchpole, K. R.; Polman, A. Design principles for particle plasmon enhanced solar cells. Applied Physics Letters 2008, 93, 191113.

6. Mahmoud, A. Y.; Zhang, J.; Ma, D.; Izquierdo, R.; Truong, V.-V. Thickness dependent enhanced efficiency of polymer solar cells with gold nanorods embedded in the photoactive layer. Solar Energy Materials and Solar Cells 2013, 116, 1-8.

7. Akimov, Y. A.; Koh, W. S. Design of plasmonic nanoparticles for efficient subwavelength light trapping in thin-film solar cells. Plasmonics 2011, 6, 155-161.

8. Polyakov, A.; Cabrini, S.; Dhuey, S.; Harteneck, B.; Schuck, P. J.; Padmore, H. A. Plasmonic light trapping in nanostructured metal surfaces. Applied Physics Letters 2011, 98, 203104.

9. Yu, E. T.; van de Lagemaat, J. Photon management for photovoltaics MRS Bulletin 2011, 36, 424-432. 
Nanomaterials and Energy

Volume 4 Issue NME2
Study of plasmonic effect in silicon solar cells

Yakubov, Zhanabergenov, Turemuratov and

Ernazarov
10. Echtermeyer, T. J.; Britnell, L.; Jasnos, P. K.; Lombardo, A.; Gorbachev, R. V.; Grigorenko, A. N.; Geim, A. K.; Ferrari, A. C.; Novoselov, K. S. Strong plasmonic enhancement of photovoltage in graphene. Nature Communications 2011, 2, 458.

11. Diukman, I.; Orenstein, M. How front side plasmonic nanostructures enhance solar cell efficiency.
Solar Energy Materials and Solar Cells 2011, 95, 2628-2631.

12. Pillai, S.; Catchpole, K. R.; Trupke, T.; Green, M. A. Surface plasmon enhanced silicon solar cells. Journal of Applied Physics 2007, 101, 093105-093108.

\section{WHAT DO YOU THINK?}

To discuss this paper, please email up to 500 words to the managing editor at nme@icepublishing.com

Your contribution will be forwarded to the author(s) for a reply and, if considered appropriate by the editor-inchief, will be published as a discussion in a future issue of the journal.

ICE Science journals rely entirely on contributions sent in by professionals, academics and students coming from the field of materials science and engineering. Articles should be within 5000-7000 words long (short communications and opinion articles should be within 2000 words long), with adequate illustrations and references. To access our author guidelines and how to submit your paper, please refer to the journal website at www.icevirtuallibrary.com/nme 